\title{
Metabolite Levels in Paediatric Brain Tumours Correlate with Histological Features
}

\author{
Eleni Orphanidou-Vlachou ${ }^{a, b}$ Sarah E. Kohe ${ }^{a, b} \quad$ Marie-Anne Brundler ${ }^{b}$ \\ Lesley MacPherson $^{b}$ Yu Sun ${ }^{a, b}$ Nigel Davies ${ }^{b, c}$ Martin Wilson ${ }^{a, b}$ \\ Xiaoyan Pan ${ }^{a, b}$ Theodoros N. Arvanitis ${ }^{b}$ d Richard G. Grundy ${ }^{e}$ \\ Andrew C. Peet ${ }^{a, b}$ \\ a Institute of Cancer and Genomic Sciences, University of Birmingham, ${ }^{b}$ Birmingham Children's Hospital NHS \\ Foundation Trust, and 'Department of Imaging and Medical Physics, University Hospital Birmingham, Birmingham, \\ d Institute of Digital Healthcare, WMG, University of Warwick, Coventry, and e Children's Brain Tumour Research \\ Centre, University of Nottingham, Nottingham, UK
}

\section{Keywords}

Magnetic resonance spectroscopy · Paediatric brain neoplasms · Histology · Ki67 · Necrosis · Apoptosis ·

Metabolites · Lipids

\begin{abstract}
Aims: Metabolite levels can be measured non-invasively using in vivo ${ }^{1} \mathrm{H}$ magnetic resonance spectroscopy (MRS). These tumour metabolite profiles are highly characteristic for tumour type in childhood brain tumours; however, the relationship between metabolite values and conventional histopathological characteristics has not yet been fully established. This study systematically tests the relationship between metabolite levels detected by MRS and specific histological features in a range of paediatric brain tumours. Methods: Single-voxel MRS was performed routinely in children with brain tumours along with the clinical imaging prior to treatment. Metabolites were quantified using LCModel. Histological features were assessed semi-quantitatively
\end{abstract}

for 27 children on H\&E and immunostained slides, blind to the metabolite values. Statistical analysis included 2-tailed independent-samples $t$ tests and 2-tailed Spearman rank correlation tests. Results: Ki67, cellular atypia, and mitosis correlated positively with choline metabolites, and phosphocholine in particular. Apoptosis and necrosis were both associated with lipid levels, with the relationship dependent on the use of long or short echo time MRS acquisitions. Neuronal components correlated negatively and glial components positively with $\mathrm{N}$-acetyl-aspartate. Glial components correlated positively with myoinositol. Conclusion: Metabolite levels in children's brain tumours measured by MRS are closely associated with key histological features routinely assessed by histopathologists in the diagnostic process. This further elucidates our understanding of this important non-invasive diagnostic tool and strengthens our understanding of the relationship between metabolites and histological features.

\section{KARGER}

(C) 2018 S. Karger AG, Basel

E-Mail karger@karger.com

www.karger.com/pat
Prof. Andrew C. Peet

Institute of Cancer and Genomic Sciences

University of Birmingham

Edgbaston, Birmingham B152TT (UK)

E-Mail a.peet@bham.ac.uk 


\section{Introduction}

Conventional magnetic resonance imagining (MRI) provides structural information on the tumour location and properties; however it provides little information on the biological properties of the tumour. Increasingly, MRI methods are being developed that provide complementary biological information in additional to standard structural information. ${ }^{1} \mathrm{H}$ magnetic resonance spectroscopy (MRS) is a technique that measures tumour metabolite profiles and these have been shown to provide a powerful non-invasive characterization of children's brain tumours [1-4]. Clinically, the tumour type is currently categorized by histopathology [5], which is the acknowledged standard against which non-invasive techniques are compared [1]. Thus, there is a need to determine how metabolite biomarkers obtained using MRS relate to established histopathological characteristics [6] and to further understand the relationship between noninvasively determined metabolite profiles and tumour biology.

In vivo MRS is increasingly being used as a non-invasive method of measuring metabolites for disease monitoring in many brain disorders including neurodegenerative diseases such as Alzheimer's and Parkinson's disease, traumatic brain injury, psychiatric disorders, and neurooncology [2, 7-12]. A growing number of studies are investigating the value of MRS for both diagnostic classification and post-treatment monitoring in brain tumours [4, 13-16]. However, whilst some studies have correlated clinical information such as tumour grade with MRS features, there are relatively few studies that have directly examined the relationship between in vivo metabolite markers and traditional histopathological measures [1721]. Even fewer studies have been undertaken in paediatric brain tumour patients $[22,23]$. There is also an increasing trend in clinical studies towards the use of short echo time MRS data that can measure a larger number of metabolites, increasing the information available and allowing detailed laboratory findings to be investigated [24-26].

The most commonly investigated metabolites in the in vivo MRS of brain tumours are $\mathrm{N}$-acetyl aspartic acid (NAA), total choline, creatine, lipids, myoinositol (mIns), glycine (Gly), taurine (Tau), glutamate, and glutamine [4, 26]. Perhaps the most evidence for an association between MRS and histology is constituted by the choline metabolites, which have been linked to cell density [27, $28]$, the Ki67 proliferation index [18, 19], and nuclear shape $[17,27]$, as well as being suggested as a marker of rapid cellular proliferation and tumour aggressiveness $[23,29,30]$. There is also substantial literature on lipid levels detected by MRS in tumours. Lipids detected by MRS reside in intracytoplasmic lipid droplets, which increase greatly in apoptosis and necrosis [31]. Very high lipid levels are detected by MRS in necrotic tumours and this has been used as an indicator of grade in adults with gliomas [31, 32]. However, extensive necrosis is rarer in childhood brain tumours and the association with MRS detectable lipids has not yet been established fully. MRS lipids have also been linked to Ki67, although this is most likely to be through an association between necrosis and grade [27].

mIns, which can be detected reliably by short echo time MRS, is a cerebral osmolyte and has been proposed as a marker of astrocytes and gliosis [26, 33]. Elevated mIns has also been shown to distinguish between grades in astrocytomas $[34,35]$. Tumour cells in astrocytic neoplasms stain intensely with antibodies to GFAP [36]; however, mIns in tumours has not yet been linked convincingly to this. Gly was detected in paediatric brain tumours in vivo by Davies et al. [37] and it has been shown to be significantly higher in high-grade versus low-grade tumours. NAA is commonly regarded as a neuronal marker as it has been found to be preferentially highly expressed in neurons rather than glial cells [38]. In addition, in vivo MRS of normal brain displays a prominent NAA peak, whilst tumours display far less $[21,26,39,40]$. However, significant amounts of NAA are found in pilocytic astrocytomas [40], and its origin in these tumours remains controversial. In diffuse tumours it may arise from normal brain.

Despite the increasing use of MRS as a valuable clinical diagnostic and prognostic tool in brain tumours, there are still very few studies that have investigated the specific relationships between metabolites detected with in vivo MRS and traditional histopathological features. As metabolites have been proposed as potential biomarkers, further investigation of their relationship to traditional histological measures is essential for validation of their biomarker value. We have examined the relationship between key metabolites in vivo and common histopathological features in a range of paediatric brain tumours at both long and short echo times. The increasing emergence of robust clinical in vivo MRS as an important diagnostic and prognostic technique makes this study timely, particularly for paediatric patients in whom non-invasive methods are highly valued. 


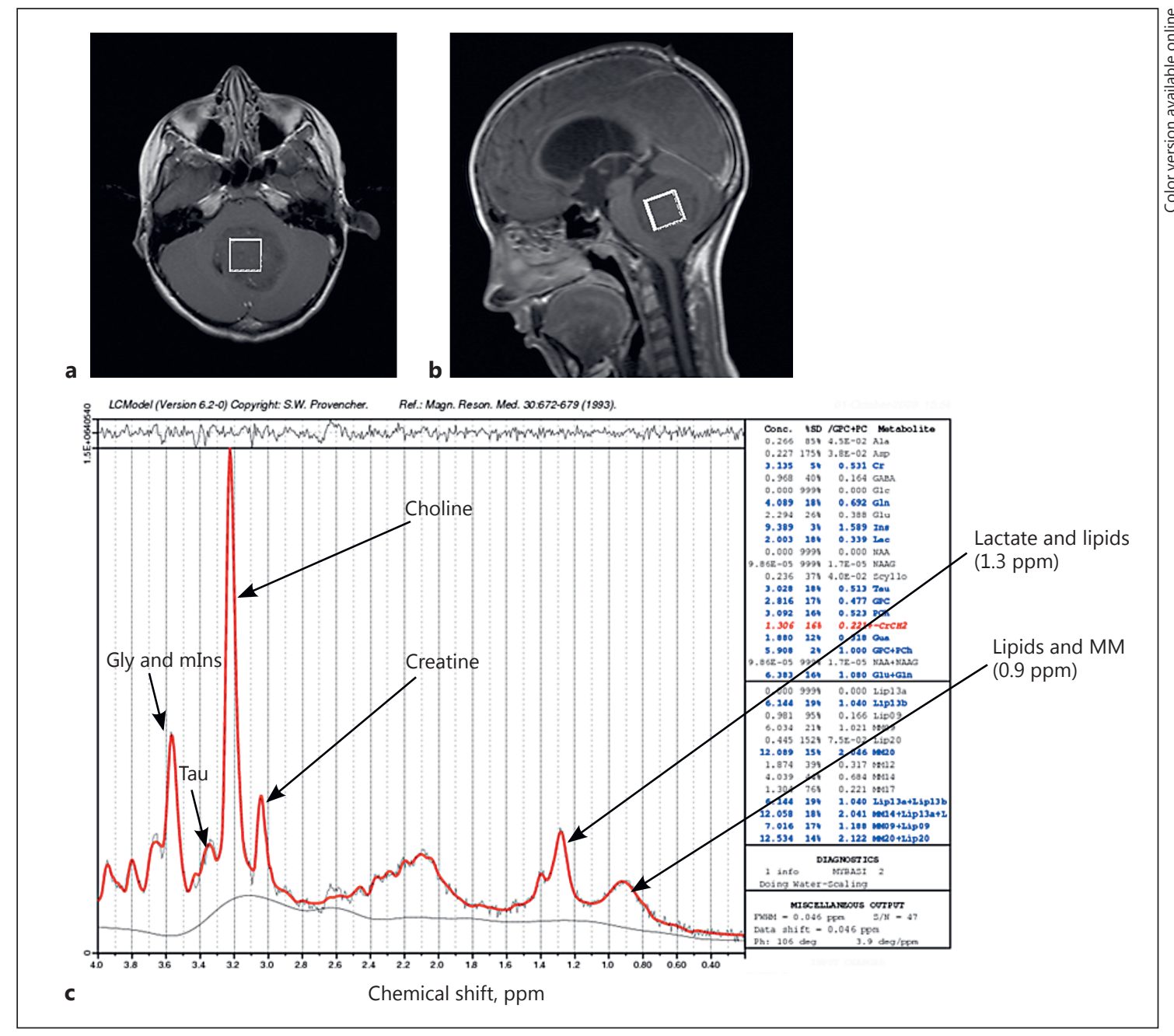

Fig. 1. Example magnetic resonance spectroscopy (MRS) spectra of a medulloblastoma tumour acquired at a short $(\mathrm{TE}=30)$ echo time. $\mathbf{a}, \mathbf{b}$ Conventional T1-weighted magnetic resonance images showing tumour in the cerebellum. The position of the voxel for acquiring MRS data is indicated by the square. c Corresponding MRS spectra with key metabolites identified and fitted in LCModel. Gly, glycine; mIns, myoinositol; Tau, taurine; MM, macromolecules; ppm, parts per million.

\section{Patients and Methods}

\section{Magnetic Resonance Spectroscopy}

MRS was performed routinely on a 1.5-T MRI scanner (Siemens Symphony or General Electric Signa Excite) in children with brain tumours combined with their clinical imaging at Birmingham Children's Hospital (BCH) from 2003 to 2009. MRS was carried out prior to any treatment (except stereotactic biopsy) and all analyses were undertaken retrospectively. Informed parental consent was obtained for the use of patient data for research purposes and ethical approval for this study was granted by the local research ethics committee (Derby NRES Committee). The acquisition protocol involved using point-resolved spectroscopy (PRESS) localization for a single voxel. The voxel volume was either 3.375 or $8 \mathrm{~cm}^{3}$ according to the size of the tumour. A TE of $30 \mathrm{~ms}$ was used for all of the patients. Some patients also had long echo time $(\mathrm{TE}=135)$ MRS acquired $(n=8)$. The repetition time was 1,500 $\mathrm{ms}$ and 128 repetitions were used for $8-\mathrm{cm}^{3}$ voxels, while $256 \mathrm{rep}$ etitions were used for $3.375-\mathrm{cm}^{3}$ voxels. A water-unsuppressed MRS was acquired for eddy current correction and as a concentration reference. Raw MRS signal data and voxel position images were transferred to a dedicated computer network. The raw MRS signal was processed using LCModel software (version 6.2.0) [41], which determines metabolite concentrations by fitting the data to a linear combination of basis functions formed from individual metabolite spectra. The unsupressed water signal was used as a concentration reference. Concentration values were calculated assuming a tissue water concentration of that for white matter. Lipid concentrations are reported per proton. An example showing metabolite fitting in LCModel in a brain tumour case from this cohort 
Table 1. Histopathological categories and respective numbers of patients (short-TE studies)

\begin{tabular}{|c|c|c|}
\hline Histopathological feature & Categories & Patients, $n$ \\
\hline Ki67 & $\begin{array}{l}<1 \% \\
1-2 \% \\
4-10 \% \\
>10 \% \\
\text { Not performed }\end{array}$ & $\begin{array}{r}7 \\
2 \\
1 \\
14 \\
3\end{array}$ \\
\hline Apoptosis & $\begin{array}{l}\text { None } \\
\text { Very low or low } \\
\text { Moderate } \\
\text { Moderate to high or high }\end{array}$ & $\begin{array}{r}4 \\
10 \\
7 \\
6\end{array}$ \\
\hline Necrosis & $\begin{array}{l}\text { Present } \\
\text { Absent }\end{array}$ & $\begin{array}{l}9 \text { (1 very localized }) \\
18\end{array}$ \\
\hline Cellular atypia & $\begin{array}{l}\text { None } \\
\text { Very low or low } \\
\text { Low to moderate or low focally moderate or moderate } \\
\text { High }\end{array}$ & $\begin{array}{l}3 \\
8 \\
8 \\
8\end{array}$ \\
\hline Mitosis & $\begin{array}{l}\text { None } \\
\text { Very low or low } \\
\text { Moderate } \\
\text { High } \\
\text { Indeterminate }\end{array}$ & $\begin{array}{l}7 \\
7 \\
7 \\
5 \\
1 \text { (removed from analysis) }\end{array}$ \\
\hline $\begin{array}{l}\text { Lesional neuronal } \\
\text { elements }\end{array}$ & $\begin{array}{l}\text { None } \\
\text { Focally PNET-like } \\
\text { Neuronal rosettes } \\
\text { Widespread PNET-like }\end{array}$ & $\begin{array}{r}13 \\
3 \\
4 \\
7\end{array}$ \\
\hline $\begin{array}{l}\text { Entrapped neuronal } \\
\text { elements }\end{array}$ & $\begin{array}{l}\text { Present } \\
\text { Absent }\end{array}$ & $\begin{array}{r}3 \\
24\end{array}$ \\
\hline $\begin{array}{l}\text { Neoplastic glial } \\
\text { elements }\end{array}$ & $\begin{array}{l}\text { None } \\
\text { Focally or entrapped } \\
\text { Predominantly glial }\end{array}$ & $\begin{array}{r}10 \\
2 \\
15\end{array}$ \\
\hline $\begin{array}{l}\text { Reactive glial } \\
\text { elements }\end{array}$ & $\begin{array}{l}\text { Present } \\
\text { Absent }\end{array}$ & $\begin{array}{l}15 \\
12\end{array}$ \\
\hline GFAP staining & $\begin{array}{l}\text { Negative } \\
\text { Very focal or reactive glial } \\
<10 \% \\
10-50 \% \\
>50 \% \\
\text { Not performed }\end{array}$ & $\begin{array}{r}2 \\
6 \\
2 \\
4 \\
11 \\
2\end{array}$ \\
\hline Vascularity & $\begin{array}{l}\text { Low } \\
\text { Moderate } \\
\text { High } \\
\text { Indeterminate }\end{array}$ & $\begin{array}{r}8 \\
14 \\
3 \\
2\end{array}$ \\
\hline Architecture & $\begin{array}{l}\text { Solid } \\
\text { Solid diffuse } \\
\text { Solid occasionally microcystic or microcystic } \\
\text { Half solid, half cystic }\end{array}$ & $\begin{array}{r}15 \\
6 \\
3 \\
3\end{array}$ \\
\hline $\begin{array}{l}\text { Synaptophysin } \\
\text { staining }\end{array}$ & $\begin{array}{l}\text { Negative } \\
\text { Scattered positive cells } \\
\text { Focally positive } \\
\text { Positive } \\
\text { Not performed }\end{array}$ & $\begin{array}{r}1 \\
1 \\
3 \\
6 \\
16\end{array}$ \\
\hline
\end{tabular}


Table 2. Summary of statistically significant correlations between histopathological features and metabolites detected by ${ }^{1} \mathrm{H}$ MRS

\begin{tabular}{|c|c|c|c|}
\hline Feature & Metabolite & Correlation $/ t$ test & $p$ values \\
\hline \multirow[t]{2}{*}{ Ki67 } & $\mathrm{PCh}$ & + ve & 0.031 \\
\hline & $\mathrm{GPC}+\mathrm{PCh}$ & $+\mathrm{ve}$ & 0.006 \\
\hline \multirow[t]{2}{*}{ Apoptosis } & Lip+MM at $0.9,1.3,2.0$, and $1.3 / 0.9 \mathrm{ppm}$ & + ve & $0.001,0.003,0.005,0.001$ \\
\hline & Tau & +ve & 0.014 \\
\hline \multirow[t]{3}{*}{ Cellular atypia } & $\mathrm{PCh}$ & $+\mathrm{ve}$ & 0.013 \\
\hline & $\mathrm{GPC}+\mathrm{PCh}$ & $+\mathrm{ve}$ & 0.014 \\
\hline & Lip $+\mathrm{MM}$ at $0.9,1.3$, and $2.0 \mathrm{ppm}$ & +ve & $0.023,0.016,0.002$ \\
\hline \multirow[t]{2}{*}{ Mitosis } & $\mathrm{PCh}$ & $+\mathrm{ve}$ & 0.004 \\
\hline & $\mathrm{Lip}+\mathrm{MM}$ at $0.9,1.3$, and $2.0 \mathrm{ppm}$ & +ve & $0.006,0.012,0.001$ \\
\hline & NAA, NAA+NAAG & $+\mathrm{ve}$ & $<0.0001$ \\
\hline GFAP & Gly & -ve & 0.003 \\
\hline
\end{tabular}

MRS, magnetic resonance spectroscopy; PCh, phosphocholine; GPC, glycerophosphocholine; Lip+MM, lipids and macromolecules; NAA, N-acetyl aspartic acid; NAAG, N-acetyl aspartate+N-acetylaspartylglutamate; mIns, myoinositol; Gly, glycine; +ve, positive correlation; -ve, negative correlation.

is presented in Figure 1. Cramer-Rao lower bounds are also determined by LCModel, and these indicate the accuracy with which the metabolite concentrations have been estimated. Metabolites and lipids with Cramer-Rao lower bounds below 30\% were accepted for accurate quantification.

The spectra were reviewed individually to assess quality, and the ones failing to meet the criterion set were excluded from the analysis. These criteria included a signal-to-noise ratio $\geq 6$ and fullwidth half-maximum $\leq 0.15 \mathrm{ppm}$. Baseline stability, good phasing, adequate water suppression, and the absence of artefacts were assessed by inspection. The voxel positioning was also reviewed to ensure that the voxel was positioned over the tumour and did not include large amounts of normal brain or cyst. In addition, voxels needed to be at least $3 \mathrm{~mm}$ away from lipid-containing bone and scalp.

\section{Segmentation}

For patients with significant amounts of cyst or ventricle in the voxel, segmentation of the T1 (pre- and post-contrast) and T2 MR images was performed and the metabolite concentrations adjusted accordingly (corrected metabolite concentration = concentration in the voxel/active tumour fraction in the voxel). The concentration of lactate was not altered in the 3 patients with cysts in the voxel (the tumour cysts contain lactate), but it was altered for the patient with a ventricle in the voxel.

\section{Histological Review}

Retrospective histological review of H\&E-stained sections obtained at the time of the biopsy or tumour resection for each patient was undertaken jointly between E.O.-V. and M.-A.B., blind to the MRS results. A single H\&E-stained section was prepared for each paraffin block. The slides assessed were representative of the tumour diagnosis and grade for all of the cases included in this study. The assessment was semi-quantitative, with each feature assigned a category. The H\&E-stained slides were assessed (with the scoring categories detailed in Table 1) for architecture and cellularity, the presence of cellular atypia, mitosis, apoptosis, and necrosis. Architecture was defined as tumour tissue with a structure that either solid, diffuse, cystic, or a combination of each. Atypia denotes the degree of abnormality within a tumour based on the degree of alteration of the shape and size of cells and nuclei compared to normal cells. Mitotic figures were defined as darkly stained elongated structures indicating chromosomes condensing and duplicating. Apoptotic cells were identified as cells with condensing and fragmenting chromatin (stained blue), often also with an irregular shape and size, as described previously [42]. Necrosis was scored as the presence or absence of tissue areas with cell shrinkage and a pronominally eosinophilic stain (stained pink) indicating DNA breakdown from dead or dying cells. Also recorded was the presence of neoplastic glial elements, reactive glial elements, entrapped neuronal elements, lesional neuronal elements (rosetting), and vascularity. Ki67, GFAP, and synaptophysin immunohistochemical stains were also reviewed where available, and the number of patients for whom this information was not available is detailed in Table 1.

Statistical analysis between metabolite levels and histopathological features was undertaken in SPSS v.17.0, using 2-tailed independent-samples $t$ tests and Spearman's rank correlation tests. $p<0.05$ was considered statistically significant. 


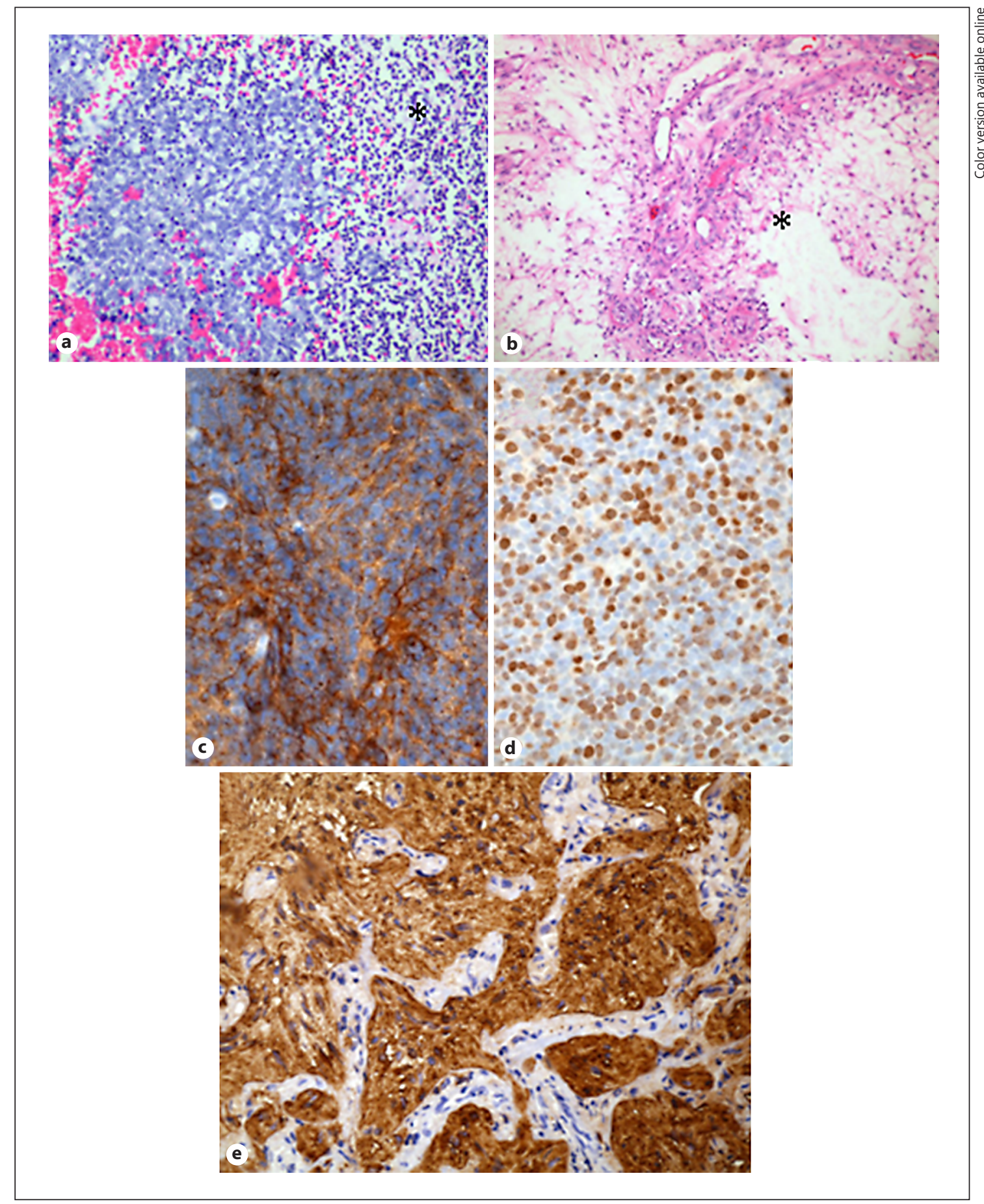

Fig. 2. Representative microphotographs illustrating pathological parameters assessed semi-quantitatively. a Classical medulloblastoma (H\&E, $\times 40$ original magnification) showing a high cellularity and high levels of apoptosis (asterisk). b Pilocytic astrocytoma $(\mathrm{H} \& \mathrm{E}$, original magnification $\times 20)$ showing low cellularity and a partly solid, partly cystic (asterisk) architecture. c Classical medulloblastoma with synaptophysin widely and strongly expressed in tumour cells. Synaptophysin is a specific marker for tissue derived from neural and neuroendocrine tissue, and positivity is indicated by brown labelling within the cell cytoplasm and membranes. d Classical medulloblastoma with high Ki67 labelling ( $>50 \%$ positive). Positive Ki67 staining is represented by the brown nuclear staining which is a specific marker of proliferating cells. e Pilocytic astrocytoma showing strong staining with GFAP, an intermediate filament protein that labels astrocytic and some ependymal cells within the central nervous system. GFAP expression is indicated by brown membranous and cytoplasmic staining of tissue. 


\section{Results}

Twenty-seven children with brain tumours were included in this study. The breakdown by tumour type (according to WHO 2007) [5] was: 9 medulloblastomas, 5 pilocytic astrocytomas, 3 ependymomas, 2 atypical teratoid/rhabdoid tumours, 2 glioblastoma, 2 diffuse astrocytomas, 2 dysembryoplastic neuroepithelial tumours, 1 pineoblastoma, and 1 gliomatosis cerebri. The categories of all of the histopathological variables and the respective number of patients in each are shown in Table 1. Representative microphotographs of the key histopathological parameters assessed are shown in Figure 2. Statistically significant correlations are summarized in Table 2.

Tumour proliferation measured by the percentage of Ki67 nuclear staining correlated positively with phosphocholine (PCh) and glycerophosphocholine+PCh (GPC+ PCh; Fig. 3c) but not GPC. Apoptosis correlated positively with lipids+macromolecules (Fig. 2) and Tau (Fig. 3b; $p<0.02$ ). For the cases where necrosis was absent $(n=18)$, statistically significant positive correlations were found between apoptosis and lipids/macromolecules at $0.9 \mathrm{ppm}\left(r_{\mathrm{s}}=0.645\right), 1.3 \mathrm{ppm}\left(r_{\mathrm{s}}=0.656\right), 2.0 \mathrm{ppm}\left(r_{\mathrm{s}}=\right.$ $0.718)$, and $1.3 / 0.9 \mathrm{ppm}\left(r_{\mathrm{s}}=0.667\right)(p<0.005)$. Tau was also significantly correlated with apoptosis in the nonnecrotic patients $\left(r_{\mathrm{s}}=0.668, p=0.002\right)$.

A comparison between the necrotic $(n=8)$ and nonnecrotic tumours $(n=18)$ found no statistically significant differences with respect to the amount of lipids+macromolecules at $0.9,1.3$, and $2.0 \mathrm{ppm}$ or lactate. However, long TE total lipids+macromolecules were found to be significantly higher in the group with necrosis $(n=2)$ compared to the group without necrosis $(n=$ 6) $(p<0.05)$. Lipids at $1.3 / 0.9$ were not significantly different between these groups. Apoptosis did not significantly correlate with lipids/macromolecules at long TE.

There was a significant positive correlation between atypia and PCh, GPC+PCh, and lipids+macromolecules. A scatter plot of atypia versus lipids+macromolecules at $2.0 \mathrm{ppm}$ is shown in Figure 3d. Mitosis also correlated positively with $\mathrm{PCh}$ and lipids+macromolecules, but not with GPC or GPC+PCh. Lesional neuronal elements correlated negatively with $\mathrm{N}$-acetyl aspartate (NAA) and $\mathrm{N}$-acetyl aspartate $+\mathrm{N}$-acetylaspartylglutamate (NAA+NAAG). No significant difference in NAA or NAA+NAAG between patients with and without entrapped neuronal elements was found. Neoplastic glial elements correlated positively with mIns (Fig. 3e), NAA, and NAA+NAAG and negatively with Gly (Fig. 3f), but not with mIns+Gly together. The concentrations of mIns,
Table 3. Summary of statistically significant correlations between metabolites detected by ${ }^{1} \mathrm{H}$ MRS and tumour grade

\begin{tabular}{llll}
\hline Metabolite & $\begin{array}{l}\text { Spearman's } \\
\text { correlation } \\
\text { coefficient }\end{array}$ & $\begin{array}{l}\text { Direction } \\
\text { of } \\
\text { correlation }\end{array}$ & $p$ value \\
\hline Creatine & 0.397 & + ve & 0.05 \\
PCh & 0.571 & + ve & 0.001 \\
GPC+PCh & 0.626 & + ve & 0.001 \\
Gly & 0.566 & + ve & 0.001 \\
Lip+MM at $0.9,1.3,2.0$ ppm & 0.617 & + ve & 0.001 \\
Lip $1.3 / 0.9$ & 0.43 & + ve & 0.05 \\
Tau & 0.39 & + ve & 0.05 \\
NAA+NAAG & 0.636 & -ve & 0.001 \\
\hline
\end{tabular}

Low grade $1, n=8$. Intermediate grade $2 / 3, n=6$. High grade $4, n=13$. MRS, magnetic resonance spectroscopy; PCh, phosphocholine; GPC, glycerophosphocholine; Lip+MM, lipids and macromolecules; NAA, N-acetyl aspartic acid; NAAG, N-acetyl aspartate $+\mathrm{N}$-acetylaspartylglutamate; mIns, myoinositol; Gly, glycine; Tau, taurine; +ve, positive correlation; -ve, negative correlation.

Gly, mIns+Gly, NAA, and NAA+NAAG were not significantly different between groups where reactive glial elements were present $(n=15)$ or absent $(n=12)(p>$ $0.07)$. GFAP correlated negatively with Gly $(p<0.003)$, but there was no significant correlation with mIns.

The vascularity and architecture of the tumours did not significantly correlate with lactate, and synaptophysin staining was not significantly correlated with NAA and NAA+NAAG. However, it should be noted that synaptophysin staining was not performed on 16 patients as it is not undertaken in tumours that are expected to be negative (e.g., in glial tumours).

There were also several significant correlations between tumour grade and metabolite concentration, in particular for PCh, lipids+macromolecules, creatine, Tau, and Gly, which were all positively associated with increasing grade (Table 3 ). In contrast, NAA+NAAG was the only metabolite with a significant negative association with increased grade $(p<0.001$; Table 3$)$.

\section{Discussion}

MRS has seen increasing use as a non-invasive tool for the characterization and monitoring of brain tumours. Although many studies have reported the relationship between metabolites and diagnostic groups, tumour ag- 




Fig. 3. Plots showing the mean metabolite concentration across categories for each histological feature. a Mean lipids and macromolecules at 0.9 ppm (MM09+Lip09) vs. apoptosis. b Mean taurine (Tau) vs. apoptosis. c Mean glycerophosphocholine+phospho- choline (GPC+PCh) vs. Ki67. d Mean lipids and macromolecules at $2.0 \mathrm{ppm}$ (MM20+Lip20) vs. atypia. e Mean myoinositol (mIns) vs. neoplastic glial elements. f Mean glycine (Gly) vs. neoplastic glial elements. mod, moderate. Error bars represent \pm 1 SE. 
gressiveness, and prognosis, few have addressed the relationship to histopathological features routinely assessed after biopsy or resection. In particular, there is a lack of studies systematically comparing the set of major morphological features assessed in routine histopathology with MRS acquired in a manner that maximizes the number of metabolites quantified. This study has found important associations between metabolites detected by in vivo MRS in paediatric brain tumours and key histological features including apoptosis, necrosis, mitosis, atypia, and glial and neuronal components.

Total choline was found to correlate positively with Ki67. Choline-containing metabolites are involved in membrane synthesis and have a role in membrane turnover [30]. Total choline elevation is thought to be a marker of malignant transformation and rapid cellular proliferation as a result of increased mitosis, leading to an abnormal increase in metabolism [17, 18, 43, 44]. Previous studies have identified a correlation between Ki67 and total choline in a variety of tumours including grade IIIV astrocytomas in adults [19], medulloblastomas in children $[23,45]$, and homogeneous, but not heterogeneous, gliomas in adults [18]. Two other studies in adult gliomas did not find a correlation between total choline and Ki67 $[27,28]$. The reason for these conflicting results has been postulated to be that PCh and GPC both contribute to total choline but it is the ratio $\mathrm{PCh} / \mathrm{GPC}$ which is related to tumour growth $[46,47]$. In the current study, a positive correlation was found between Ki67 and PCh but not GPC, supporting this assertion. In addition, both atypia and mitosis, also features of tumour aggressiveness, had significant correlations with $\mathrm{PCh}$, although only atypia correlated with total choline. The determination of PC and GPC by ${ }^{1} \mathrm{H}$ MRS at $1.5 \mathrm{~T}$ in vivo is far less robust than for tCho, and results for these metabolites should be interpreted with caution. There is some evidence that values for PC and GPC from ${ }^{1} \mathrm{H}$ MRS at $1.5 \mathrm{~T}$ reflect those seen in these tumours $[1,47,48]$ and so we have included them here for completeness. Recent evidence has begun to link underlying patterns of gene expression to in vivo and ex vivo choline metabolism in breast cancer subgroups $[49,50]$. This further emphasises the importance of the choline metabolites as biomarkers in all tumours. Our work suggests that choline metabolism may play an important role in cellular proliferation and membrane turnover in paediatric brain tumours, thus warranting continued investigation.

Atypia and mitosis were found to have significant correlations with lipids in the current study. Lipids measured by MRS are known to be higher in more aggressive tu- mours and associated with a poor survival $[14,51]$. Lipids have also been associated with apoptosis $[31,52,53]$, an active process of programmed cell death during which large intracellular lipid droplets accumulate that are detected by MRS $[54,55]$. High lipids were associated with necrosis as well as apoptosis and this association was dependent on the MRS technique used to acquire the data. Lipids measured by short echo time MRS correlated with apoptosis, whereas lipid concentrations measured by long echo time MRS were higher in the necrotic tumours. Short echo time MRS is very sensitive for the detection of lipids and it is likely that this is important in detecting the signals from the small lipid droplets which experience some motion restriction of the fatty acid chains [54]. The less sensitive long echo time MRS is well suited to detecting the large levels of more mobile lipids associated with necrosis. Prior associations between lipids and necrosis have largely been found with long echo time data $[31,56]$. The current findings suggest that altering the MRS technique between short and long echo time sequences may be useful for elucidating the relative contribution of lipids arising from apoptosis and necrosis, respectively, although further work will be required to conclusively determine this.

Tau was also found to be positively correlated with apoptosis although there is less information in the literature regarding this association. Ex vivo tissue metabolite analysis and histopathological analysis performed by Opstad et al. [57] found Tau to significantly correlate with apoptotic cell density in necrotic and non-necrotic biopsies of adult gliomas. In a model of apoptotic death in cultured cerebellar granule neurons, Tau was found to be implicated in cell shrinkage during apoptosis [58]. In further support of this, Lang et al. [59] loaded Jurkat human T lymphocytes with Tau and were able to induce apoptotic cell death. The resulting Tau release coincided and presumably contributed to the cell shrinkage typical of apoptotic death and preceded DNA fragmentation.

Although NAA is commonly regarded as a putative neural marker and a measure of neural density and function, its origin in tumours is less certain, with prior evidence of prominent NAA peaks in tumours of astrocytic origin $[19,45,60]$. Interestingly, we found a significant positive correlation between NAA and neoplastic glial elements and a significant negative correlation between NAA and lesional neuronal elements. As NAA was most prominent in pilocytic astrocytomas, this result supports the assertion that the NAA seen in these tumours arises from tumour tissue rather than from neurons entrapped within the tumour $[61,62]$. Furthermore, scrutiny of the 
voxel positions confirms that the NAA cannot be explained by normal-appearing brain from within or close to the voxel. The origin of NAA in astrocytoma cells may be linked to O-2A progenitor cells which contain NAA $[40,63]$. These cells are precursors of type 2 astrocytes, and some low-grade astrocytomas express antigens consistent with the type 2 astrocytic lineage [64].

mIns was found to correlate positively with neoplastic glial elements, consistent with studies which have shown mIns to be high in glial tumours and a potential astrocytic marker $[9,34,35,45,60]$. There was no correlation between mIns and GFAP expression, although they are both considered to be markers of glial differentiation. This is in agreement with Öz et al. [65], who investigated GFAP levels in the CSF of patients with spinocerebellar ataxia type 1 and their relationship to metabolites from different brain locations. The lack of correlation between GFAP and $\mathrm{mIns}$ is perhaps unsurprising given that GFAP histological expression can be highly variable in astrocytic tumours [66].

In this study lactate was not found to correlate with tumour architecture, necrosis, or vascularity. Although some studies have reported an association between lactate and tumour necrosis, others have detected very little correlation between lactate and histological tumour properties [21, 44, 67-69]. It is likely that lactate detected in vivo in brain tumours is a measure of abnormal metabolic activity and not exclusively linked to tumour necrosis. The significant association between tumour grade and individual metabolites such as total choline, PCh, lipids and macromolecules, Gly, and Tau is also consistent with prior work, with elevated levels of these metabolites previously reported in high-grade brain tumours [14, 37, $45,47,70]$. An association between increased NAA in low-grade glial tumours has also been previously identified [71].

As metabolite profiles are increasingly being used to both classify and monitor disease progression in paediatric brain tumours, it is important to examine the association between such metabolites and traditional histological markers. This will aid in the interpretation of MRS metabolite measures in tumours and increase our understanding of the biological underpinnings of metabolites as potential biomarkers of disease. Metabolites also add additional information beyond that associated with diagnosis alone, including prognostic information useful for risk stratification, monitoring of relapsed tumours which are rarely re-biopsied and examined histologically, and distinguishing relapse from treatment-related effects which would otherwise be very difficult using conven- tional MRI. Furthering our understanding of the relationship between histology and metabolites in resected brain tumours will also aid in the interpretation of MRS in cases where biopsy and/or resection is not routinely undertaken.

In summary, we have tested the association between metabolite levels determined by in vivo MRS and routinely assessed histopathological features in paediatric brain tumours. The results confirm previous findings from in vitro and animal studies. Previous in vivo clinical studies have been restricted to the investigation of a small number of metabolites in gliomas in adults. In vivo MRS is a powerful non-invasive method for the characterization of paediatric brain tumours and gives information that correlates well with important histopathological features such as proliferation index, apoptosis, and necrosis. Larger multicentre studies in the paediatric population will enable these correlations to be tested in specific tumour types.

\section{Acknowledgments}

We would like to thank the members of the Radiology and Histopathology Departments at Birmingham Children's Hospital who helped with this study. Finally, we thank the Samantha Dickson Brain Tumour Trust (17/31), The Brain Tumour Charity (GN2181), Action Medical Research (GN2181), Children with Cancer (15/188), Cancer Research UK, the Engineering and Physical Sciences Research Council Cancer Imaging Programme at the Children's Cancer and Leukaemia Group (CCLG) in association with the Medical Research Council and Department of Health (UK) (C7809/A10342), the National Institute for Health Research, Poppy Fields Appeal, the Andrew McCartney Trust Fund for Brain Tumour Research, and Birmingham Children's Hospital Charities for funding this work. A.C.P. is funded by a research professorship from the National Institute for Health Research. The study sponsors had no involvement in the preparation of this manuscript.

\section{Disclosure Statement}

All authors declare no conflicts of interest. 


\section{References}

1 Davies NP, Wilson M, Harris LM, Natarajan K, Lateef S, Macpherson L, Sgouros S, Grundy RG, Arvanitis TN, Peet AC: Identification and characterisation of childhood cerebellar tumours by in vivo proton MRS. NMR Biomedicine 2008;21:908-918.

2 Peet AC, Arvanitis TN, Auer DP, Davies NP, Hargrave D, Howe FA, Jaspan T, Leach MO, Macarthur D, Macpherson L, Morgan PS, Natarajan K, Payne GS, Saunders D, Grundy RG; CCLG Functional Imaging Group: The value of magnetic resonance spectroscopy in tumour imaging. Arch Dis Child 2008;93:725727.

3 Peet AC, Leach MO, Pinkerton CR, Price P, Williams SR, Grundy RG: Proceedings of the Engineering and Physical Sciences Research Council Workshop - the development of functional imaging in the diagnosis, management and understanding of childhood brain tumours. Pediatr Blood Cancer 2005;44:103-113.

4 Vicente J, Fuster-Garcia E, Tortajada S, García-Gómez JM, Davies N, Natarajan K, Wilson M, Grundy RG, Wesseling P, Monleón D, Celda B, Robles M, Peet AC: Accurate classification of childhood brain tumours by ${ }^{1} \mathrm{H}$ MRS: a multi-centre study. Eur J Cancer 2013; 49:658-667.

5 Louis DN, Ohgaki H, Wiestler OD, Cavenee WK, Burger PC, Jouvet A, Scheithauer BW, Kleihues P: The 2007 WHO classification of tumours of the central nervous system. Acta Neuropathologica 2007;114:97-109.

6 Astrakas LG, Zurakowski D, Tzika AA, Zarifi MK, Anthony DC, De Girolami U, Tarbell NJ, Black PM: Noninvasive magnetic resonance spectroscopic imaging biomarkers to predict the clinical grade of pediatric brain tumors. Clin Cancer Res 2004;10:8220-8228.

7 Stan AD, Ghose S, Zhao C, Hulsey K, Mihalakos P, Yanagi M, Morris SU, Bartko JJ, Choi $\mathrm{C}$, Tamminga CA: Magnetic resonance spectroscopy and tissue protein concentrations together suggest lower glutamate signaling in dentate gyrus in schizophrenia. Mol Psychiatry 2015;20:433-439.

8 Maudsley AA, Govind V, Levin B, Saigal G, Harris L, Sheriff S: Distributions of magnetic resonance diffusion and spectroscopy measures with traumatic brain injury. J Neurotrauma 2014;32:1056-1063.

9 Harris JL, Choi I-Y, Brooks WM: Probing astrocyte metabolism in vivo: proton magnetic resonance spectroscopy in the injured and aging brain. Front Aging Neurosci 2015;7:202.

10 Buonocore Michael H, Maddock Richard J: Magnetic resonance spectroscopy of the brain: a review of physical principles and technical methods. Rev Neurosci 2015;26: 609-632.

11 García-Figueiras R, Baleato-González S, Padhani AR, Oleaga L, Vilanova JC, Luna A, Gómez JCC: Proton magnetic resonance spectroscopy in oncology: the fingerprints of cancer? Diagn Interv Radiol 2016;22:75-89.
12 Zanigni S, Testa C, Calandra-Buonaura G, Sambati L, Guarino M, Gabellini A, Evangelisti S, Cortelli P, Lodi R, Tonon C: The contribution of cerebellar proton magnetic resonance spectroscopy in the differential diagnosis among parkinsonian syndromes. Parkinsonism Relat Disord 2015;21:929-937.

13 Wilson M, Gill SK, Macpherson L, English M, Arvanitis TN, Peet AC: Non-invasive detection of glutamate predicts survival in pediatric medulloblastoma. Clin Cancer Res 2014;20: 4532-4539.

14 Wilson M, Cummins CL, Macpherson L, Sun Y, Natarajan K, Grundy RG, Arvanitis TN, Kauppinen RA, Peet AC: Magnetic resonance spectroscopy metabolite profiles predict survival in paediatric brain tumours. Eur J Cancer 2013;49:457-464.

15 De la Fuente MI, Young RJ, Rubel J, Rosenblum M, Tisnado J, Briggs S, Arevalo-Perez J, Cross JR, Campos C, Straley K, Zhu D, Dong C, Thomas A, Omuro AA, Nolan CP, Pentsova E, Kaley TJ, Oh JH, Noeske R, Maher E, Choi C, Gutin PH, Holodny AI, Yen K, Deangelis LM, Mellinghoff IK, Thakur SB: Integration of 2-hydroxyglutarate-proton magnetic resonance spectroscopy into clinical practice for disease monitoring in isocitrate dehydrogenase-mutant glioma. Neuro Oncol 2016;18: 283-290.

16 Blüml S, Margol AS, Sposto R, Kennedy RJ, Robison NJ, Vali M, Hung LT, Muthugounder S, Finlay JL, Erdreich-Epstein A, Gilles FH, Judkins AR, Krieger MD, Dhall G, Nelson MD, Asgharzadeh S: Molecular subgroups of medulloblastoma identification using noninvasive magnetic resonance spectroscopy. Neuro Oncol 2016;18:126-131.

17 Nafe R, Herminghaus S, Pilatus U, Hattingen E, Marquardt G, Schlote W, Lanfermann H, Zanella F: Morphology of proliferating and non-proliferating tumor cell nuclei in glioblastomas correlates with preoperative data from proton-MR-spectroscopy. Neuropathology 2004;24:172-182.

18 Shimizu H, Kumabe T, Shirane R, Yoshimoto $\mathrm{T}$ : Correlation between choline level measured by proton MR spectroscopy and Ki-67 labeling index in gliomas. Am J Neuroradiol 2000;21:659-665.

19 Tamiya T, Kinoshita K, Ono Y, Matsumoto K, Furuta T, Ohmoto T: Proton magnetic resonance spectroscopy reflects cellular proliferative activity in astrocytomas. Neuroradiology 2000;42:333-338.

20 Dowling C, Bollen AW, Noworolski SM, McDermott MW, Barbaro NM, Day MR, Henry RG, Chang SM, Dillon WP, Nelson SJ, Vigneron DB: Preoperative proton MR spectroscopic imaging of brain tumors: correlation with histopathologic analysis of resection specimens. Am J Neuroradiol 2001;22:604-612.

21 Oshiro S, Tsugu H, Komatsu F, Abe H, Onishi H, Ohmura T, Iwaasa M, Sakamoto S, Fukushima T: Quantitative assessment of gliomas by proton magnetic resonance spectroscopy. Anticancer Res 2007;27:3757-3763.

22 Harris LM, Davies NP, Macpherson L, Lateef S, Natarajan K, Brundler M-A, Sgouros S, English MW, Arvanitis TN, Grundy RG, Peet AC: Magnetic resonance spectroscopy in the assessment of pilocytic astrocytomas. Eur J Cancer 2008;44:2640-2647.

23 Peet AC, Davies NP, Ridley L, Brundler M-A, Kombogiorgas D, Lateef S, Natarajan K, Sgouros S, Macpherson L, Grundy RG: Magnetic resonance spectroscopy suggests key differences in the metastatic behaviour of medulloblastoma. Eur J Cancer 2007;43: 1037-1044.

24 Peet AC, Lateef S, Macpherson L, Natarajan K, Sgouros S, Grundy RG: Short echo time ${ }^{1} \mathrm{H}$ magnetic resonance spectroscopy of childhood brain tumours. Childs Nerv Syst 2007; 23:163-169.

25 Majos C, Julia-Sape M, Alonso J, Serrallonga M, Aguilera C, Acebes JJ, Arus C, Gili J: Brain tumor classification by proton MR spectroscopy: comparison of diagnostic accuracy at short and long TE. AJNR Am J Neuroradiol 2004;25:1696-1704.

26 Verma A, Kumar I, Verma N, Aggarwal P, Ojha R: Magnetic resonance spectroscopy revisiting the biochemical and molecular milieu of brain tumors. BBA Clin 2016;5:170178.

27 Nafe R, Herminghaus S, Raab P, Wagner S, Pilatus U, Schneider B, Schlote W, Zanella F, Lanfermann $\mathrm{H}$ : Preoperative proton-MR spectroscopy of gliomas - correlation with quantitative nuclear morphology in surgical specimen. J Neurooncol 2003;63:233-245.

28 Gupta RK, Cloughesy TF, Sinha U, Garakian J, Lazareff J, Rubino G, Rubino L, Becker DP, Vinters HV, Alger JR: Relationships between choline magnetic resonance spectroscopy, apparent diffusion coefficient and quantitative histopathology in human glioma. J Neurooncol 2000;50:215-226.

29 Stenman K, Stattin P, Stenlund H, Riklund K, Gröbner G, Bergh A: ${ }^{1} \mathrm{H}$ HRMAS NMR derived bio-markers related to tumor grade, tumor cell fraction, and cell proliferation in prostate tissue samples. Biomark Insights 2011;6:39-47.

30 Glunde K, Bhujwalla ZM, Ronen SM: Choline metabolism in malignant transformation. Nat Rev Cancer 2011;11.

31 Opstad KS, Bell BA, Griffiths JR, Howe FA: An investigation of human brain tumour lipids by high-resolution magic angle spinning ${ }^{1} \mathrm{H}$ MRS and histological analysis. NMR Biomed 2008;21:677-685.

32 Howe FA, Barton SJ, Cudlip SA, Stubbs M, Saunders DE, Murphy M, Wilkins P, Opstad KS, Doyle VL, Mclean MA, Bell BA, Griffiths JR: Metabolic profiles of human brain tumors using quantitative in vivo ${ }^{1} \mathrm{H}$ magnetic resonance spectroscopy. Magn Reson Med 2003; 49:223-232. 
33 Fisher SK, Novak JE, Agranoff BW: Inositol and higher inositol phosphates in neural tissues: homeostasis, metabolism and functional significance. J Neurochem 2002;82:736-754.

34 Castillo M, Smith JK, Kwock L: Correlation of myo-inositol levels and grading of cerebral astrocytomas. Am J Neuroradiol 2000;21:16451649.

35 Metwally LIA, El-Din SE, Abdelaziz O, Hamdy IM, Elsamman AK, Abdelalim AM: Predicting grade of cerebral gliomas using myoinositol/creatine ratio. Egypt J Radiol Nucl Med 2014;45:211-217.

36 Marsden HB, Kumar S, Kahn J, Anderton BJ: A study of glial fibrillary acidic protein (GFAP) in childhood brain tumours. Int J Cancer 1983;31:439-445.

37 Davies NP, Wilson M, Natarajan K, Sun Y, Macpherson L, Brundler MA, Arvanitis TN, Grundy RG, Peet AC: Non-invasive detection of glycine as a biomarker of malignancy in childhood brain tumours using in-vivo ${ }^{1} \mathrm{H}$ MRS at 1.5 tesla confirmed by ex-vivo highresolution magic-angle spinning NMR. NMR Biomed 2010;23:80-87.

38 Nadler JV, Cooper JR: N-acetyl-L-aspartic acid content of human neural tumours and bovine peripheral nervous tissues. J Neurochem 1972;19:313-319.

39 Blüml S, Wisnowski JL, Nelson MD, Paquette L, Gilles FH, Kinney HC, Panigrahy A: Metabolic maturation of the human brain from birth through adolescence: insights from in vivo magnetic resonance spectroscopy. Cereb Cortex 2013;23:2944-2955.

40 Moffett JR, Ross B, Arun P, Madhavarao CN, Namboodiri MA: N-acetylaspartate in the CNS: from neurodiagnostics to neurobiology. Prog Neurobiol 2007;81:89-131.

41 Provencher SW: Estimation of metabolite concentrations from localized in vivo proton NMR spectra. Magn Reson Med 1993;30:672-679.

42 Kohe S, Brundler M-A, Jenkinson H, Parulekar M, Wilson M, Peet AC, McConville CM: Metabolite profiling in retinoblastoma identifies novel clinicopathological subgroups. $\mathrm{Br} \mathrm{J}$ Cancer 2015;113:1216-1224

43 Chen J, Huang S-L, Li T, Chen X-L: In vivo research in astrocytoma cell proliferation with ${ }^{1} \mathrm{H}$-magnetic resonance spectroscopy: correlation with histopathology and immunohistochemistry. Neuroradiology 2006;48: 312-318.

44 Crawford FW, Khayal IS, McGue C, Saraswathy S, Pirzkall A, Cha S, Lamborn KR, Chang SM, Berger MS, Nelson SJ: Relationship of pre-surgery metabolic and physiological MR imaging parameters to survival for patients with untreated GBM. J Neurooncol 2009;91:337-351.

45 Panigrahy A, Krieger MD, Gonzalez-Gomez I, Liu X, McComb JG, Finlay JL, Nelson MD, Gilles FH, Blüml S: Quantitative short echo time ${ }^{1} \mathrm{H}$-MR spectroscopy of untreated pediatric brain tumors: preoperative diagnosis and characterization. Am J Neuroradiol 2006; $27: 560-572$
46 Mirbahai L, Wilson M, Shaw CS, McConville C, Malcomson RDG, Griffin JL, Kauppinen RA, Peet AC: ${ }^{1} \mathrm{H}$ magnetic resonance spectroscopy metabolites as biomarkers for cell cycle arrest and cell death in rat glioma cells. Int J Biochem Cell Biol 2011;43:990-1001.

47 Wilson M, Davies N, Brundler M-A, McConville C, Grundy R, Peet A: High resolution magic angle spinning ${ }^{1} \mathrm{H}$ NMR of childhood brain and nervous system tumours. Mol Cancer 2009;8:6.

48 Wilson M, Davies NP, Grundy RG, Peet AC: A quantitative comparison of metabolite signals as detected by in vivo MRS with ex vivo ${ }^{1} \mathrm{H}$ HR-MAS for childhood brain tumours. NMR Biomed 2009;22:213-219.

49 Grinde M, Skrbo N, Moestue S, Rødland E, Borgan E, Kristian A, Sitter B, Bathen T, Børresen-Dale A-L, Maelandsmo G, Engebraaten O, Sørlie T, Marangoni E, Gribbestad I: Interplay of choline metabolites and genes in patient-derived breast cancer xenografts. Breast Cancer Res 2014;16:R5.

50 Moestue SA, Borgan E, Huuse EM, Lindholm EM, Sitter B, Børresen-Dale AL, Engebraaten O, Maelandsmo GM, Gribbestad IS: Distinct choline metabolic profiles are associated with differences in gene expression for basal-like and luminal-like breast cancer xenograft models. BMC Cancer 2010;10:433.

51 Marcus KJ, Astrakas LG, Zurakowski D, Zarifi MK, Mintzopoulos D, Poussaint TY, Anthony DC, De Girolami U, Black PM, Tarbell NJ, Tzika AA: Predicting survival of children with CNS tumors using proton magnetic resonance spectroscopic imaging biomarkers. Int J Oncol 2007;30:651-657.

52 Hakumaki J, Kauppinen R: ${ }^{1} \mathrm{H}$ NMR visible lipids in the life and death of cells. Trends Biochem Sci 2000;25:357-362.

53 Hakumaki J, Poptani H, Sandmair A, YlaHerttuala S, Kauppinen R: ${ }^{1} \mathrm{H}$ MRS detects polyunsaturated fatty acid accumulation during gene therapy of glioma: implications for the in vivo detection of apoptosis. Nat Med 1999;5:1323-1327.

54 Pan X, Wilson M, McConville C, Arvanitis T, Kauppinen R, Peet A: The size of cytoplasmic lipid droplets varies between tumour cell lines of the nervous system: a ${ }^{1} \mathrm{H}$ NMR spectroscopy study. MAGMA 2012;25:479-485.

55 Mirbahai L, Wilson M, Shaw CS, McConville C, Malcomson RDG, Kauppinen RA, Peet AC: Lipid biomarkers of glioma cell growth arrest and cell death detected by ${ }^{1} \mathrm{H}$ magic angle spinning MRS. NMR Biomed 2012;25: 1253-1262.

56 Kuesel A, Sutherland G, Halliday W, Smith I: ${ }^{1} \mathrm{H}$ MRS of high grade astrocytomas: mobile lipid accumulation in necrotic tissue. NMR Biomed 1994;7:149-155.

57 Opstad KS, Bell BA, Griffiths JR, Howe FA: Taurine: a potential marker of apoptosis in gliomas. Br J Cancer 2009;100:789-794.
58 Morán J, Hernández-Pech X, Merchant-Larios $\mathrm{H}$, Pasantes-Morales $\mathrm{H}$ : Release of taurine in apoptotic cerebellar granule neurons in culture. Pflugers Arch 2000;439:271-277.

59 Lang F, Madlung J, Uhlemann CA, Risler T, Gulbins E: Cellular taurine release triggered by stimulation of the Fas(CD95) receptor in Jurkat lymphocytes. Pflugers Arch 1998;436: 377-383.

60 Cuellar-Baena S, Morales JM, Martinetto H, Calvar J, Sevlever G, Castellano G, Monleon D: Comparative metabolic profiling of paediatric ependymoma, medulloblastoma and pilocytic astrocytoma. Int J Mol Med 2010;26: 941-948.

61 Barker PB: N-acetyl aspartate - a neuronal marker? Ann Neurol 2001;49:423-424.

62 Ross B, Blüml S: Magnetic resonance spectroscopy of the human brain. Anat Rec 2001; 265:54-84.

63 Urenjak J, Williams SR, Gadian DG, Noble M: Specific expression of $\mathrm{N}$-acetylaspartate in neurons, oligodendrocyte-type-2 astrocyte progenitors, and immature oligodendrocytes in vitro. J Neurochem 1992;59:55-61.

64 Piepmeier JM, Fried I, Makuch R: Low-grade astrocytomas may arise from different astrocyte lineages. Neurosurgery 1993;33:627632.

65 Öz G, Hutter D, Tkáč I, Clark HB, Gross MD, Jiang H, Eberly LE, Bushara KO, Gomez CM: Neurochemical alterations in spinocerebellar ataxia type 1 and their correlations with clinical status. Mov Dis 2010;25:1253-1261.

66 Halliday GM, Cullen KM, Kril JJ, Harding AJ, Harasty J: Glial fibrillary acidic protein (GFAP) immunohistochemistry in human cortex: a quantitative study using different antisera. Neurosci Lett 1996;209:29-32.

67 Kugel H, Heindel W, Ernestus RI, Bunke J, Mesnil RD, Friedmann G: Human brain tumors: spectral patterns detected with localized H-1 MR spectroscopy. Radiology 1992; 183:701-709.

68 Walenta S, Wetterling M, Lehrke M, Schwickert G, Sundfor K, Rofstad E, Mueller-Klieser W: High lactate levels predict likelihood of metastases, tumor recurrence, and restricted patient survival in human cervical cancers. Cancer Res 2000;60:916-921.

69 Van der Graaf M: In vivo magnetic resonance spectroscopy: basic methodology and clinical applications. Eur Biophys J 2010;39:527-540.

70 McKnight TR, Lamborn KR, Love TD, Berger MS, Chang S, Dillon WP, Bollen A, Nelson SJ: Correlation of magnetic resonance spectroscopic and growth characteristics within grades II and III gliomas. J Neurosurg 2007; 106:660-666.

71 Law M, Yang S, Wang H, Babb JS, Johnson G, Cha S, Knopp EA, Zagzag D: Glioma grading: sensitivity, specificity, and predictive values of perfusion MR imaging and proton MR spectroscopic imaging compared with conventional MR imaging. Am J Neuroradiol 2003;24:1989-1998. 